\title{
Discover the Cosmos - Bringing Cutting Edge Science to Schools across Europe
}

\author{
Rosa Doran \\ NUCLIO - Núclio Interactivo de Astronomia \\ Largo dos Topázios, 48, 3 Frt, 2785-817 S. D. Rana, Portugal
}

\begin{abstract}
The fast growing number of science data repositories is opening enormous possibilities to scientists all over the world. The emergence of citizen science projects is engaging in science discovery a large number of citizens globally. Astronomical research is now a possibility to anyone having a computer and some form of data access. This opens a very interesting and strategic possibility to engage large audiences in the making and understanding of science. On another perspective it would be only natural to imagine that soon enough data mining will be an active part of the academic path of university or even secondary schools students. The possibility is very exciting but the road not very promising. Even in the most developed nations, where all schools are equipped with modern ICT facilities the use of such possibilities is still a very rare episode. The Galileo Teacher Training Program GTTP, a legacy of IYA2009, is participating in some of the most emblematic projects funded by the European Commission and targeting modern tools, resources and methodologies for science teaching. One of this projects is Discover the Cosmos which is aiming to target this issue by empowering educators with the necessary skills to embark on this innovative path: teaching science while doing science.
\end{abstract}

Keywords. Miscellaneous, sociology of astronomy

The Galileo Teacher Training Program (GTTP), a cornerstone of IYA2009, and a strong legacy, aims to build a strong support network for educators around the world. Partnering with skilled trainers and scientists we are establishing a sustainable structure to act as a 24 hour helpdesk to teachers all over the world. The scheme is to carefully build the basis of this structure in every nation and scaffold the effort via an effective cascade mechanism where teachers train other teachers. GTTP has such building blocks in 100 nations having reached over 15000 teachers so far.

The possibility to participate in projects such as:

- Discover the Cosmos (DtC) (http://www.discoverthecosmos.eu)

- European Hands-on Universe (EUHOU) (http://www.euhou.net)

- Open Discovery Space (ODS) (http://www.opendiscoveryspace.eu)

allows a more quickly and effective growth of the basic structure and training opportunities as well as gathering precious information regarding the usability of modern tools and resources for science teaching. By understanding the limitations faced by educators: curriculum wise, lack of ICT competences or equipment, etc., as well as existing opportunities in terms of school infrastructure and freedom to introduce innovation in classroom, DtC, EUHOU and ODS are constructing and documenting the roadmap for the classroom of tomorrow.

The above mentioned projects open the possibility to introduce students and educators to data repositories and science facilities and invite them to engage in real research exercises while learning curriculum content. The suggested resources and projects are built using a modern approach to science teaching, based on replication the scientific method, the inquiry method. 
Resources are being created making use of data archives and structuring lessons that have as an end result a scientific outcome. One such example is the Asteroid Search, a program promoted by the International Astronomical Search Collaboration that involves students in the discovery or follow-up of small bodies of the Solar System (asteroids, comets, etc.). Data mining programs such as: CosmoQuest (http://cosmoquest.org/) , ZooUniverse (http://zooniverse.org/), Aladin (http://aladin.u-strasbg.fr/) or World Wide Telescope (http://www.worldwidetelescope.org/) are also integrated in our suggestions to educators. The use of infrastructures for science teaching is another possibility being presented to educators such as radio antennas (http://euhou.obspm.fr/public/) or robotic telescopes (http://www.faulkes-telescope.com/).

Despite the fact that the resources are freely available and some of them very successful among the public in general, statistics show that educators are not using them as a teaching tool. Several are the reasons for this: lack of training, inadaptability to curriculum, lack of classroom time, etc. GTTP aim is precisely to empower educators to use such tools and resources, to help them localize and adapt materials to their educational panorama. Our training events are the entry door to a joint path where further training, new tools and resources, sharing spaces and peer support is always available.

GTTP takes the mission further by engaging the science community to support this enterprise and commit to the production of useful material, and eventually receiving useful contributions to their own research. This collaborative effort (schools x science community) is a win-win situation where students awake for the beauty of science and learn science while doing science. This fast growing community of stakeholders in each of the participating nations: trainers, teachers, students, scientists and education authorities is a promising vision for construction of a community of educators with innovative competences, capable of taking part of this new trend for education: the construction of the classroom of tomorrow. 